\title{
Monomer Elution from Three Resin Composites at Two Different Time Interval Using High Performance Liquid Chromatography-An In-Vitro Study
}

\author{
Krishnamachari Janani ${ }^{1}$, Kavalipurapu Venkata Teja ${ }^{2} \mathbb{D}$, Raghu Sandhya ${ }^{2, *}$, Mohammad Khursheed Alam ${ }^{3} \mathbb{D}$, \\ Ruba K. Al-Qaisi ${ }^{4}\left(\mathbb{D}\right.$, Deepti Shrivastava ${ }^{5, *}{ }^{(D)}$, Mohammed Odhayd Alnusayri ${ }^{6}$, Zainab Ali Alkhalaf ${ }^{6}$, \\ Mohammed G. Sghaireen ${ }^{6}$ and Kumar Chandan Srivastava ${ }^{7, * \mathbb{D}}$
}

check for updates

Citation: Janani, K.; Teja, K.V.; Sandhya, R.; Alam, M.K.; Al-Qaisi, R.K.; Shrivastava, D.; Alnusayri, M.O.; Alkhalaf, Z.A.; Sghaireen, M.G.; Srivastava, K.C. Monomer Elution from Three Resin Composites at Two Different Time Interval Using High Performance Liquid Chromatography-An In-Vitro Study. Polymers 2021, 13, 4395. https:// doi.org/10.3390/polym13244395

Academic Editor: Evangelia Vouvoudi

Received: 8 November 2021 Accepted: 12 December 2021 Published: 15 December 202

Publisher's Note: MDPI stays neutral with regard to jurisdictional claims in published maps and institutional affiliations.

Copyright: (c) 2021 by the authors. Licensee MDPI, Basel, Switzerland. This article is an open access article distributed under the terms and conditions of the Creative Commons Attribution (CC BY) license (https:// creativecommons.org/licenses/by/ $4.0 /)$.
1 SRM Institute of Science and Technology, SRM Dental College, Chennai 600089, Tamil Nadu, India; jananik6@srmist.edu.in

2 Department of Conservative Dentistry and Endodontics, Saveetha Dental College \& Hospitals, Saveetha Institute of Medical \& Technical Sciences, Saveetha University, Chennai 600077, Tamil Nadu, India; venkatatejak.sdc@saveetha.com

3 Orthodontics, Department of Preventive Dentistry, College of Dentistry, Jouf University, Sakaka 72345, Saudi Arabia; mkalam@ju.edu.sa

4 Prosthodontic Dentistry Department, Jordanian Royal Medical Services, Amman 962507, Jordan; rkqaisi@gmail.com

5 Periodontics, Department of Preventive Dentistry, College of Dentistry, Jouf University, Sakaka 72345, Saudi Arabia

6 Prosthodontic Dentistry Department, College of Dentistry, Jouf University, Sakaka 72345, Saudi Arabia; dr.moalnusayri@jodent.org (M.O.A.); dr.zainab.alkhalaf@jodent.com (Z.A.A.); dr.mohammed.sghaireen@jodent.org (M.G.S.)

7 Oral Medicine \& Radiology, Department of Oral \& Maxillofacial Surgery \& Diagnostic Sciences, College of Dentistry, Jouf University, Sakaka 72345, Saudi Arabia

* Correspondence: drsandhyaendo@gmail.com (R.S.); sdeepti20@gmail.com (D.S.); drkcs.omr@gmail.com (K.C.S.); Tel.: +966-500782498 (D.S.); +966-536217990 (K.C.S.)

Abstract: Esthetics, improved colour stability and ease of contour have made photo-activated resin based restorative materials being widely used in routine dental clinical practice. Perhaps improper and inadequate polymerization of resin based composite material might lead to elution of monomer. Thus, the aim of the current study was to quantify the monomer elution from three resin composites. The intended analysis was made using high performance liquid chromatography (HPLC) at two different time periods. Three different materials that were investigated in the current study included Swiss Tech resin composite (Group A), Ceram X (Group B) and Beautifil Injectable composite (Group C). Ten cylindrical samples were fabricated in each study group. In $75 \%$ wt of ethanol, the samples were ingressed immediately and stored at room temperature. A $0.5 \mathrm{~mL}$ of the samples was assessed at pre-defined time intervals at $24 \mathrm{~h}$ and 7 th day. Later, assessment of the samples was performed with HPLC and the data was analyzed using statistical test. Bisphenol A-glycidyl methacrylate (Bis-GMA), Triethylene glycol dimethacrylate (TEGDMA), 2-hydroxyethyl methacrylate (HEMA) and Urethane dimethacrylate (UDMA) were quantified in the samples. When analyzing the release monomer, it was found that at the end of $24 \mathrm{~h}$ Bis-GMA was eluted more in the injectable resin composite whereas, TEGDMA was eluted from Swiss Tech and Ceram X resin composites. At the end of the 7th day it was evident that Bis-GMA was eluted maximum in all the three resin composites. Thus, monomer release was found to be evident among all three resin composites and it is of utmost important to be assessed in routine clinical practice.

Keywords: dental restorations; Bis-GMA; bulk fill composites; conventional resin composites; high performance liquid chromatography; monomer release; residual monomer 


\section{Introduction}

There has been a great enthusiasm over recent decades in the use of tooth colored restoration. Resin composites are found to be potential alternative in replacing mercury containing amalgam restoration as a result of its esthetics and toxicological properties [1]. Resin matrix, inorganic fillers monomers, initiators and coupling agents constitute the composition of resin composites [2,3]. The most frequently used monomers are dimethacrylate such as bisphenol-A glycol dimethacrylate (Bis-GMA) and urethane dimethacrylate (UDMA) which are used since early $60 s^{\prime}$. In recent years, to minimize the water absorption and polymerization shrinkage other composites were introduced [4]. Such composites are very viscous and therefore diluents such as triethylene glycol dimethacrylate (TEGDMA) were added [5].

During polymerization, conversion of monomer to polymer is termed as degree of conversion [6]. In other words, degree of conversion means the percentage of reacted $\mathrm{C}=\mathrm{C}$ bond from the monomers present in polymeric matrices. Percentage of $\mathrm{C}=\mathrm{C}$ bond calculated from the ratio of cured to uncured monomer is related to internal standard $[7,8]$. A hundred percent degree of conversion occurs when all monomer gets converted into polymer; however the conversion of all the monomer to polymer is never complete. The percentage of conversion usually ranges from $43-70 \%$. The free monomer accounts for $10 \%$ elution from resin composite [9]. The degree of conversion depends upon the intrinsic factors such as concentration of photo initiator, chemical structure of the monomer and extrinsic factor such as polymerization conditions [10]. Factors which can influence the degree of conversion and are under the clinician's control include the intensity of light from light curing unit, duration of irradiation light and the restorative material thickness [9].

The degree of conversion is inversely correlated with the unreacted monomer which in turn affects the solubility of resin composites. The solubility has an influence on the resistance to degradation in the oral environment [11]. Therefore, this property becomes critical as it affects the biocompatibility of the material at this stage. Decrease in the degree of conversions leads to increase in the elution of monomer into the oral environment and thus adversely affects the physical and mechanical property of the material [12].

The amount of eluting species ranges between 0.5 and $2 \% \mathrm{wt}$ in water, $2-6 \% \mathrm{wt}$ in $70 \%$ ethanol and $10 \%$ in methanol [13]. Various solvents employed to analyze the release of monomers include distilled water, saliva, ethanol, methanol and acetonitrile [14]. In the present study, ethanol was used as solvent which not only has the solubility parameter matching to that of Bis-GMA but it also matches to the oral environment for the detection of monomer elution. It was reported that unreacted monomers are said to be released when the ethanol penetrates the resin matrix and the space between the polymer chains expands [15].

Biocompatibility of the material gets affected when there is an increased release of monomer as the resin matrix consists of 20 to $40 \%$ of monomer. TEGDMA upon elution causes secondary caries by increasing the growth of cariogenic bacteria [16]. TEGDMA is reported to have cytotoxic effect as it can penetrate and react with intercellular molecules. Furthermore, it can creep into the membrane and can react with intracellular molecules. It is also identified as the primary component released from cured dental composites.

Bisphenol-A is reported to have a hormonal activity and has shown to affect the estrogen hormone leading to female infertility. Methacrylate monomers are very reactive in nature and in particular in-vitro research has shown that they may adversely interact with oral cells. Reactive oxygen species disturbs the redox homeostasis eventually disturbing the function of vital cells [17]. They are not only cytotoxic at high concentrations, but they also have been associated with genotoxicity [18]. Due to its chemical structure and hydrolic nature, Bis-GMA has shown a strong hemolytic potency.

Incremental layering technique enhances degree of conversion and increase in the percentage of monomer to polymer conversion when cured at the depth of $2 \mathrm{~mm}$. On the other hand, the disadvantages of this technique include the inclusion of voids or impurities between composite layers, bond failures between increments, insertion difficulty due to 
limited access in the small cavities and the requirement of additional time [19]. Unreacted monomer and other degradation products can be analyzed using high performance liquid chromatography (HPLC), gas chromatography, electrospray ionization and mass spectrometry (19). Ceram X (Dentsply, Konstanz, Germany) and Beautifil Injectable (Shofu Inc, Kyoto, Japan) are the two bulk fill resin composite which has been introduced recently.

Therefore, the aim of the study was to quantify the monomer elution of three resin composites. The analysis was made with the help of HPLC at two different time periods.

\section{Materials and Methods}

An in-vitro study was performed. The three different composites used in the current study were categorised into three study groups with a sample size of ten $(n=10)$ for each group. The solvent used in the study was ethanol. Table 1 lists the technical profiles of the three distinct composites employed in the investigation.

Table 1. Technical profiles of the composites tested in the current study.

\begin{tabular}{|c|c|c|c|c|}
\hline Composite & Manufacturer & Polymer & Filler Content \% vol & Filler Content $\%$ wt \\
\hline $\begin{array}{l}\text { Swiss Tech } \\
\text { (Group A) }\end{array}$ & Coltene & $\begin{array}{c}\text { Bis-GMA } \\
\text { UDMA, TEGDMA, } \\
\text { HEMA }\end{array}$ & 89 & 73 \\
\hline $\begin{array}{c}\text { Ceram X } \\
\text { (Group B) }\end{array}$ & $\begin{array}{c}\text { Injectable } \\
\text { Liechtenstein }\end{array}$ & $\begin{array}{c}\text { Bis-GMA } \\
\text { UDMA, TEGDMA, } \\
\text { HEMA }\end{array}$ & 62 & 81 \\
\hline $\begin{array}{l}\text { Injectable } \\
\text { (Group C) }\end{array}$ & Shofu & $\begin{array}{c}\text { Bis-GMA } \\
\text { UDMA, TEGDMA, } \\
\text { HEMA }\end{array}$ & 68.6 & 83.3 \\
\hline
\end{tabular}

Note: Bis-GMA—dimethacrylate such as bisphenol-A glycol dimethacrylate; UDMA—urethane dimethacrylate; TEGDMA-Triethylene glycol dimethacrylate; HEMA-2-hydroxyethyl methacrylate.

- Group A-Swiss Tech resin composite (Coltenewhaledent Pvt Ltd., Wazirpur, New Delhi, India)

- Group B-Ceram X (Dentsply Sirona, De-Trey-Straße 1, 78467 Konstanz, Germany)

- $\quad$ Group C-Beautifil Injectable (Shofu Inc., Fukuine, Higashiyama-ku, Kyoto, Japan)

\subsection{Sample Preparation}

Teflon moulds were used to make the samples, allowing for the creation of standardized cylindrical specimens ( $4 \mathrm{~mm}$ thickness and $5 \mathrm{~mm}$ diameter). The corresponding resin composite materials were placed into the moulds. For all study groups the resin composite was placed by incremental layering technique of $2 \mathrm{~mm}$ thickness and cured. By applying pressure to the extra resin composite material, a glass slide was placed on top to assure flat surfaces. It also reduces the amount of oxygen that inhibits the polymerization reaction. The resin composite samples were polymerized for $20 \mathrm{~s}$ using a light-emitting diode unit in the standard curing mode, with an output wavelength ranging from 395-480 nm and $1000 \mathrm{~mW} / \mathrm{cm}^{2}$ output irradiance. Following fabrication, ten samples from each group were immersed in a $75 \%$ wt ethanol/water solution as an extraction fluid and stored at room temperature in environmental chamber at $34{ }^{\circ} \mathrm{C}$ and $70 \%$ relative humidity. It is necessary to maintain the relative humidity in order to be equivalent to oral environment. $0.5 \mathrm{~mL}$ of ethanol sample was taken for HPLC analysis at predefined time intervals: $24 \mathrm{~h}$ (T1), and 7 th day (T2). No other conditioning methods were taken for storing at $24 \mathrm{~h}$ and 7 th day as it was only stored in ethanol solvent in order to assess the release of monomer.

\subsection{High-Performance Liquid Chromatography (HPLC) Analysis}

The samples were analyzed using HPLC (SHIMADZU, Model SPD 20A, Shimadzu Corporation, Nakagyo-ku, Kyoto, Japan). Liquid chromatographic grade ethanol and acetonitrile were used. The release of monomers was detected using reverse phase HPLC 
equipment. An EC 125/4 Nucleodur 100-5 C18 HPLC-Column was used to separate monomers. Ingredient of elution and composition of the mobile phase has been altered during the course of the chromatographic run. The composition of the mobile phase is increased gradually during the elution process. At a flow rate of $1 \mathrm{~mL} / \mathrm{min}$, the mobile phase was $80 \%$ acetonitrile and $20 \%$ ultrapure water, and detection was done at a wavelength of $254 \mathrm{~nm}$. Loops with a capacity of $25 \mu \mathrm{L}$ were injected. For the chromatographic peaks at the relevant retention time (RT) vs. monomer concentration, linear fits of the calibration curves were produced. The relationship between concentration and absorbance was displayed using calculated areas under the peak. The percentages of different polymers in each study group were calculated (Table 2).

Table 2. Monomer elution from three resins composite at different time interval.

\begin{tabular}{cccc}
\hline \multirow{3}{*}{ Study Group } & Polymers & $\mathbf{2 4} \mathbf{h}$ & 7th Day \\
\cline { 3 - 4 } & & $\mathbf{\%}$ of Monomer Release & \% of Monomer Release \\
\hline \multirow{4}{*}{ Ceram X } & HEMA & 24.4 & 0 \\
& TEGDMA & 28.8 & 42.8 \\
& UDMA & 6.28 & 3.5 \\
& Bis-GMA & 12.8 & 49.0 \\
\hline \multirow{3}{*}{ Swiss Tech } & HEMA & 10.1 & 0 \\
& TEGDMA & 61.5 & 37.0 \\
& UDMA & 0.6 & 3.6 \\
& Bis-GMA & 24.25 & 57.3 \\
\hline \multirow{3}{*}{ Injectable } & HEMA & 0 & 0 \\
& TEGDMA & 42.1 & 38.7 \\
& UDMA & 5.3 & 3.5 \\
& Bis-GMA & 43.2 & 51.3 \\
\hline
\end{tabular}

Note: Bis-GMA—dimethacrylate such as bisphenol-A glycol dimethacrylate; UDMA—urethane dimethacrylate; TEGDMA-Triethylene glycol dimethacrylate; HEMA -2-hydroxyethyl methacrylate.

\subsection{Statistical Analysis}

The collected data were analyzed with IBM SPSS statistics software 23.0 Version (IBM SPSS predictive analytics community, Armonk, NY, USA). One-way ANOVA with Tukey's post-hoc test was used for the intergroup analysis for each time interval $24 \mathrm{~h}$ and 7 th day. Intragroup paired comparison was also carried out with paired t-test to assess the monomer release.

\section{Results}

Inter-group comparison after $24 \mathrm{~h}$ revealed higher overall monomer release from Swiss Tech resin composite followed by injectable composite and Ceram X. Evaluating the monomer release after $24 \mathrm{~h}$ from Group A, it was found that higher amount of TEGDMA was eluted, followed by Hydroxy ethyl methacrylate (HEMA), Bis-GMA, and UDMA. Within Group B, it was found that TEGDMA was eluted more than Bis-GMA and the least was UDMA. In case of Group C, Bis-GMA was reported to be eluted more than TEGDMA (Figure 1A-F). 

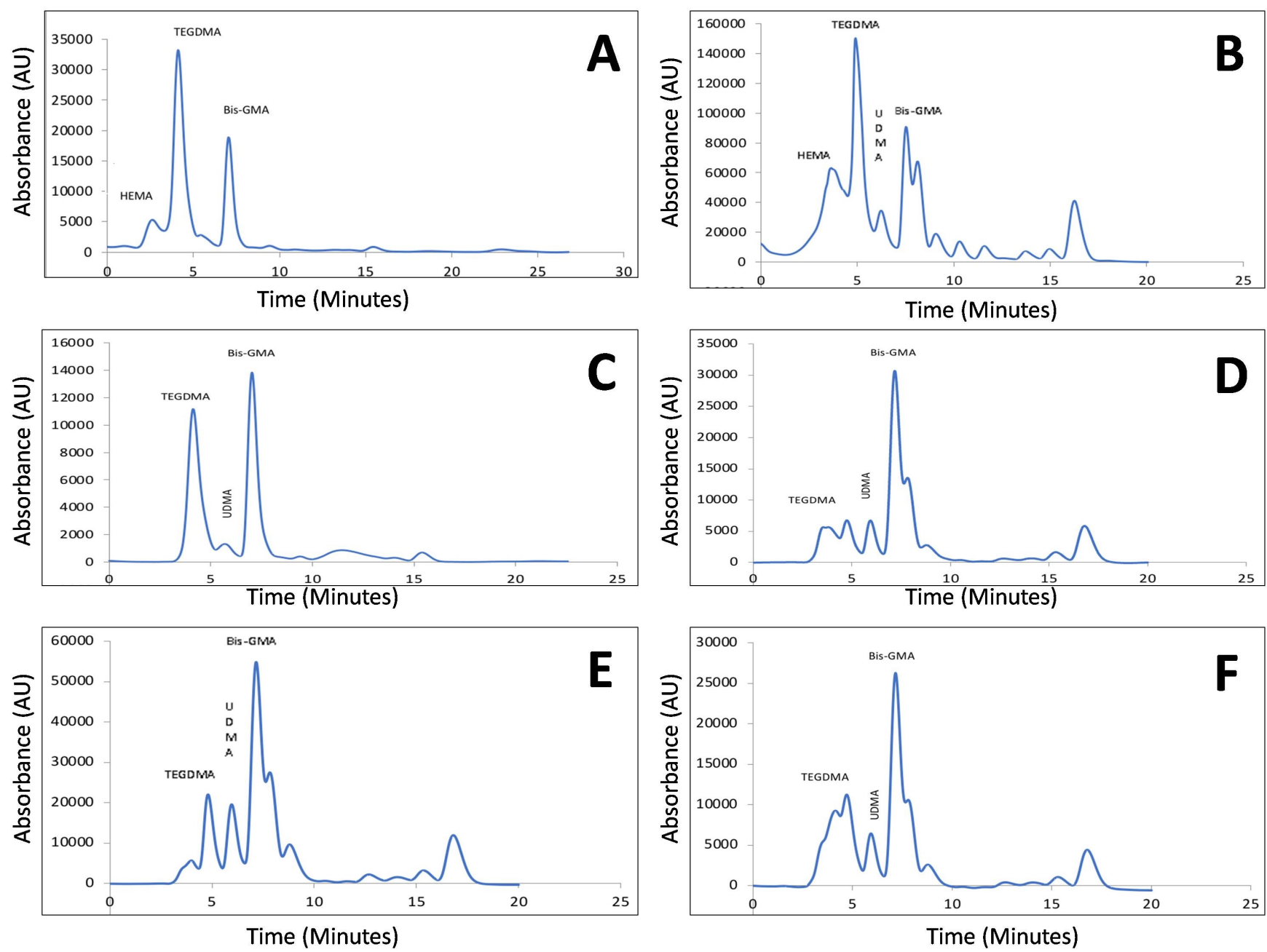

Figure 1. (A-F): Monomer Elution From Different Resin Composite At Two Different Time Interval Using High-Performance Liquid Chromatography (A) Ceram X composite Resin after 24 h; (B) Swiss Tech Resin Composite after 24 h; (C) Injectable Resin Composite after 24 h; (D) Ceram X Resin Composite after 7th day; (E) Swiss Tec after 7th day; (F) Injectable resin composite after 7 th day.

After 7th day, in all three resin composites it was found that the most eluted monomer was Bis-GMA. The next eluted monomer was TEGDMA and least was found to be UDMA (Figure 1A-F). Paired t-test was used to quantify the monomer release as mentioned in the table (Table 3). Analysis of variance with Tukey's post-hoc test revealed there was statistically significant difference in monomer release (Tables 4 and 5).

Table 3. Intragroup comparative evaluation of the monomer elution from three resin composites at different time interval.

\begin{tabular}{cccc}
\hline \multirow{2}{*}{ Study Group } & \multicolumn{2}{c}{ Time Interval } & \multirow{2}{p}{$\begin{array}{c}p \text { Value } \\
\text { (Interpretation) }\end{array}$} \\
\cline { 2 - 3 } & $\mathbf{2 4 ~ h}$ & 7th Day & \\
\hline Ceram X & $10.01 \pm 5.7$ & $10.02 \pm 5.7$ & $p>0.05 ;$ (NS) \\
\hline Swiss Tech & $13.02 \pm 7.5$ & $13.04 \pm 7.5$ & $p>0.05 ;(\mathrm{NS})$ \\
\hline Injectable & $11.3 \pm 6.5$ & $13.3 \pm 9.5$ & $p<0.000 ;(\mathrm{VHS})$ \\
\hline
\end{tabular}

Note: Results expressed in Mean \pm Standard Deviation; NS-Not significant; VHS—Very High Significance. 
Table 4. Inter group comparative evaluation of the monomer elution from three resin composite at different time interval.

\begin{tabular}{|c|c|c|c|c|c|}
\hline Time Period & Groups & Sum of Squares & df & Mean Square & $p$ Value \\
\hline \multirow{3}{*}{$24 \mathrm{~h}$} & Between the groups & $12,822.49$ & 2 & 6411.246 & \multirow{3}{*}{$0.0005^{* * *}$} \\
\hline & Within group & $374,781.90$ & 8254 & 45.406 & \\
\hline & Total & $387,604.39$ & 8256 & & \\
\hline \multirow{3}{*}{ 7th Day } & Between the groups & $12,809.68$ & 2 & 6404.842 & \multirow{3}{*}{$0.0005^{* * *}$} \\
\hline & Within group & $374,781.90$ & 8254 & 45.406 & \\
\hline & Total & $387,591.59$ & 8256 & & \\
\hline
\end{tabular}

Note: ${ }^{* * *} p$ value $<0.001$; One-way ANOVA.

Table 5. Post-Hoc Intergroup comparative evaluation of the monomer elution from three resincomposite at different time interval.

\begin{tabular}{|c|c|c|c|c|c|}
\hline \multirow{2}{*}{ Time Interval } & \multirow{2}{*}{ Study Group } & \multirow{2}{*}{$\begin{array}{l}\text { Comparison } \\
\text { Study Group }\end{array}$} & \multirow{2}{*}{$p$ Value } & \multicolumn{2}{|c|}{ 95\% Confidence Interval } \\
\hline & & & & Lower Bound & Upper Bound \\
\hline \multirow{6}{*}{ Day 7} & \multirow{2}{*}{ Ceram X } & Swiss Tech & $0.0005^{* * *}$ & -3.457266 & -2.601068 \\
\hline & & Injectable & $0.0005^{* * *}$ & -1.729678 & -0.845322 \\
\hline & \multirow{2}{*}{ Swiss Tech } & Ceram X & $0.0005^{* * *}$ & 2.601068 & 3.457266 \\
\hline & & Injectable & $0.0005^{* * *}$ & 1.327570 & 2.155763 \\
\hline & \multirow{2}{*}{ Injectable } & Ceram X & $0.0005^{* * *}$ & 0.845322 & 1.729678 \\
\hline & & Swiss Tech & $0.0005^{* * *}$ & -2.155763 & -1.327570 \\
\hline \multirow{6}{*}{ Day 24} & \multirow{2}{*}{ Ceram X } & Swiss Tech & $0.0005^{* * *}$ & -3.457266 & -2.601068 \\
\hline & & Injectable & $0.0005^{* * *}$ & -1.738011 & -0.853656 \\
\hline & \multirow{2}{*}{ Swiss Tech } & Ceram X & $0.0005 * * *$ & 2.601068 & 3.457266 \\
\hline & & Injectable & $0.0005^{* * *}$ & 1.319237 & 2.147430 \\
\hline & \multirow{2}{*}{ Injectable } & Ceram X & $0.0005^{* * *}$ & 0.853656 & 1.738011 \\
\hline & & Swiss Tech & $0.0005^{* * *}$ & -2.147430 & -1.319237 \\
\hline
\end{tabular}

Note: ${ }^{* * *} p$ value $<0.001$; Tukey's Post-Hoc analysis.

\section{Discussion}

The release of monomers may have an impact on the material's structural stability, biocompatibility, and wear rate. The most important factors for monomer elution are the chemistry of the solvent, size, chemical nature of the liberated components and the level of polymerization [20]. It can also be due to polymer matrix composition, filler particle type, content, resin porosity and homogeneity. Monomer release from the resin composite can be best evaluated by using HPLC than other methods such as gas chromatography, electrospray ionization, and mass spectroscopy [21]. HPLC, liquid chromatography-mass spectrometry (LC-MS), and gas chromatography (GC) are commonly used to identify the released components. For chemicals that can evaporate, it is advisable to utilize GC under normal circumstances. HPLC and LC-MS, on the other hand are better for samples with a high molecular weight, such as Bis-GMA and UDMA or that have a high potential to degrade when heated [22]. Additionally, the HPLC is faster, efficient, and accurate in the detection of monomer elution from the sample. Hence, in the current study HPLC was employed for the purpose of estimation of elution from the resin composites. The study aimed to assessed and compared monomer release from two packable and one injectable form of resin composite.

The majority of investigations employed artificial saliva, pure water, ethanol, methanol and acetonitrile as solvents. The amount of eluted monomer from a resin composite is said to be dependent upon the solvent [13]. Water and solvents such as ethanol, methanol and acetonitrile create a comparable environment in the oral cavity [3]. United States Federal 
Drug Administration has graded 75\% ethanol-water solution as a clinical oral simulating liquid and it has been used in several studies [14]. In the present study, the rationale for using ethanol as a solvent was the ability of unreacted monomers to penetrate the matrix and widens the gap between polymer chains, thus allowing the soluble compounds to diffuse [23]. It can mimic and accelerate the typical degradation as expected clinically from the food and saliva through continual exposure [24]. Some chemicals in materials are remnants from the syntheses of raw materials and are not intentionally added during manufacture. However, this monomer can be discovered not only in ethanol-based eluates but also in water eluates.

Composite restoration in the oral cavity is said to release various components. These components are reported to cause cytotoxic, mutagenic, genotoxic and estrogenic effects [25,26]. The unpolymerized monomer has reported to reach the pulp thereby causing adverse pulpal reactions. The cytotoxicity was graded amongst all the monomer and was Bis-GMA was found to be more cytotoxic followed by UDMA, TEGDMA and HEMA [27,28]. Oxidative stress and depletion of cellular glutathione (GSH) occurs due to the toxicity of a number of dental materials to pulp cells [29]. The toxicity of methacrylates found in resin composites has been linked to GSH depletion and has been demonstrated to be mitigated by the promoter of GSH production and N-acetylcysteine. Bis-GMA causes toxicity to dental pulp cells, which gets exacerbated by the GSH synthesis inhibitor buthionine sulfoximine and mitigated by the GSH booster 2-oxothiazolidine-4- carboxylic acid [30]. Also, cellular stress gets created due to cytotoxicity of the restorative materials [31]. The appearance of free radicals, the initiation of apoptosis and tissue death are caused due to formation of cellular stress [32,33].

The size of the monomer molecule greatly influences the monomer release. Increased amount of monomer was reported to release with smaller size monomer molecule. Among the monomers, TEGDMA has a smaller molecular size and has hydrophilic property. Due to this property, TEGDMA gets liberated at a faster rate and was predominantly released from resin composite [34-36]. Due to enzymatic breakdown of monomer, higher amount of monomer gets liberated in the oral cavity when compared to that water. Studies have showed that TEGDMA and Bis-GMA were released in small quantities in water-based media compared to human saliva [37]. During polymerization, the monomers trapped in micropores in polymerized resin are more sensitive to elution than those trapped inside the microgel. If the volume of micropores is larger, then the solvent can penetrates the matrix more easily, thus cause widening of the gaps between polymer chains. A monomer can be eluted from a substance if it is soluble in the extraction medium. Thus, the concentration of eluted monomers and the rate at which they are eluted from the material are influenced not only by the percentage of unreacted monomers, but also by resin structure and monomer position within the polymer network. Tuna et al. [25] reported that the main monomer released was TEGDMA from all the samples whereas UDMA was released from only one group of material and Bis-GMA was not found in any samples. The degree of conversion of unreacted monomers and the regulation of its release using various procedures on various dental materials is a subject of ongoing research [38].

However, the results of the current study showed that at the end of $24 \mathrm{~h}$ in Swiss Tech resin composite group there was more release of TEGDMA followed by Bis-GMA, HEMA and UDMA. From injectable resin composite there was more elution of Bis-GMA followed by TEGDMA and UDMA. When we assess the monomer release after 7th day, it was evident that Bis-GMA was eluted more in all three resin composites followed by TEGDMA. Also, it was found that HEMA was eluted least to almost nil. The difference the monomer release amongst different resin composites can be due to various abovementioned factors and also might be due to resin structure and the location of the monomer within the polymer network. The polymerized composite under the mylar matrix includes a surface layer rich in low molecular weight monomers. These smaller monomers are readily released after immersion in the extraction liquid. The removal of this layer by polishing could result in less TEGDMA being released from polished samples [39]. Ac- 
cording to Yap et al. [40], any release that happens after $24 \mathrm{~h}$ of restoration is attributable to the hydrolysis process. The current investigation found that Bis-GMA eluted at a considerably higher percentage after 7 th day. This finding is consistent with those of Olga Polydorou et al. and Komurcuoglu et al., who found that Bis-GMA was released more than TEGDMA [41,42].It could be owing to the difference in chemical characteristics and reactive potentials between Bis-GMA and TEGDMA, as Bis-GMA has a lower double bond conversion than TEGDMA [43]. Another reason could be the solution that was used to keep the samples in storage.

Ortengren et al. [2] examined the elution of monomers from resin-based materials with storage durations ranging from $4 \mathrm{~h}$ to 180 days, finding that the maximum monomer concentration was attained after seven days. Even after two weeks of ageing, several routinely used resin-based restorative materials continued to release considerable levels of mass into artificial saliva. Within $24 \mathrm{~h}, 85-100 \%$ of monomers are eluted, according to Ferracane and Condon [14]. Furthermore, more recent HPLC studies have shown that monomer elution for resin-based composites lasted longer than $24 \mathrm{~h}$.

\section{Strength, Limitations, and Future Directions}

The strength of this present study is that assessment of monomer release was performed from three different resins composite, two packable composites and one injectable resin composite. There are very limited reports on monomer release from injectable resin composite. The quantification of monomer eluted was evaluated using HPLC, which is also considered as standardized method of assessment. However, in the present study, the evaluation of the monomer elution was assessed only at two-time interval. It is necessary to assess the release of monomer to identify till what time period monomer elution was present. In the present study ethanol was used as solvent, hence future studies can be concentrated on the usage of artificial saliva as a solvent in such a way it might be translatable to clinical situation.

\section{Conclusions}

Elution of monomer was found in all three composite resins at both time periods. Amongst all three composite Bis-GMA was released more followed by TEGDMA, UDMA and HEMA after 7th day. Therefore, it is essential to assess the amount of monomer release in composite resin and measures have to be taken to reduce the elution of monomer.

Author Contributions: Conceptualization, K.J., K.V.T. and R.S.; methodology, K.J., R.S. and K.V.T.; software, K.J. and K.V.T.; validation, R.S., M.K.A. and R.K.A.-Q.; formal analysis, K.V.T. and K.C.S.; investigation, K.J., K.V.T. and R.S.; resources K.J., K.V.T., K.C.S., D.S. and R.S.; data curation, K.J., K.V.T. and R.S.; writing-original draft preparation, K.J., K.V.T., K.C.S. and D.S.; writing-review and editing, K.J., K.V.T.,K.C.S., D.S., R.S., M.K.A., R.K.A.-Q., M.O.A., Z.A.A. and M.G.S.; visualization, K.J., M.O.A., Z.A.A. and M.G.S.; supervision, R.S. and K.C.S.; funding acquisition, K.J. and K.V.T. All authors have read and agreed to the published version of the manuscript.

Funding: This research received no external funding.

Institutional Review Board Statement: The study was conducted according to the guidelines of the Declaration of Helsinki, and approved by the Institutional Human Ethical Committee of Saveetha dental college \& hospitals (IHEC/SDC/FACULTY/21/ENDO/105).

Informed Consent Statement: Not applicable.

Data Availability Statement: The data set used in the current study will be made available on reasonable request.

Conflicts of Interest: The authors declare no conflict of interest. 


\section{References}

1. Goldberg, M. In vitro and in vivo studies on the toxicity of dental resin components: A review. Clin. Oral Investig. 2008, 12, 1-8. [CrossRef]

2. Ortengren, U.; Wellendorf, H.; Karlsson, S.; Ruyter, I.E. Water sorption and solubility of dental composites and identification of monomers released in an aqueous environment. J. Oral Rehabil. 2001, 28, 1106-1115. [CrossRef]

3. Ferracane, J.L. Hygroscopic and hydrolytic effects in dental polymer networks. Dent. Mater. Off. Publ. Acad. Dent. Mater. 2006, 22, 211-222. [CrossRef] [PubMed]

4. Zhou, X.; Huang, X.; Li, M.; Peng, X.; Wang, S.; Zhou, X.; Cheng, L. Development and status of resin composite as dental restorative materials. J. Appl. Polym. Sci. 2019, 136, 48180. [CrossRef]

5. Wang, X.; Cai, Q.; Zhang, X.; Wei, Y.; Xu, M.; Yang, X.; Ma, Q.; Cheng, Y.; Deng, X. Improved performance of BisGMA/TEGDMA dental composites by net-like structures formed from $\mathrm{SiO}_{2}$ nanofiber fillers. Mater. Sci. Eng. C 2016, 59, 464-470. [CrossRef] [PubMed]

6. Balagopal, S.; Geethapriya, N.; Anisha, S.; Hemasathya, B.A.; Vandana, J.; Dhatshayani, C. Comparative evaluation of the degree of conversion of four different composites polymerized using ultrafast photopolymerization technique: An in vitro study. $J$. Conserv. Dent. 2021, 24, 77. [CrossRef]

7. Lempel, E.; Őri, Z.; Kincses, D.; Lovász, B.V.; Kunsági-Máté, S.; Szalma, J. Degree of conversion and in vitro temperature rise of pulp chamber during polymerization of flowable and sculptable conventional, bulk-fill and short-fibre reinforced resin composites. Dent. Mater. 2021, 37, 983-997. [CrossRef]

8. Taher, R.M.; Moharam, L.M.; Amin, A.E.; Zaazou, M.H.; El-Askary, F.S.; Ibrahim, M.N. The effect of radiation exposure and storage time on the degree of conversion and flexural strength of different resin composites. Bull. Natl. Res. Cent. 2021, 45, 146. [CrossRef]

9. Witzel, M.F.; Calheiros, F.C.; Gonçalves, F.; Kawano, Y.; Braga, R.R. Influence of photoactivation method on conversion, mechanical properties, degradation in ethanol and contraction stress of resin-based materials. J. Dent. 2005, 33, 773-779. [CrossRef]

10. Leprince, J.G.; Palin, W.M.; Hadis, M.A.; Devaux, J.; Leloup, G. Progress in dimethacrylate-based dental composite technology and curing efficiency. Dent. Mater. Off. Publ. Acad. Dent. Mater. 2013, 29, 139-156. [CrossRef]

11. Unsal, K.A.; Karaman, E. Effect of Additional Light Curing on Colour Stability of Composite Resins. Int. Dent. J. 2021. Available online: https: / /www.sciencedirect.com/science/article/pii/S0020653921001325 (accessed on 2 December 2021). [CrossRef]

12. Schulz, S.D.; Laquai, T.; Kümmerer, K.; Bolek, R.; Mersch-Sundermann, V.; Polydorou, O. Elution of Monomers from Provisional Composite Materials. Int. J. Polym. Sci. 2015, 2015, e617407. [CrossRef]

13. Spahl, W.; Budzikiewicz, H.; Geurtsen, W. Determination of leachable components from four commercial dental composites by gas and liquid chromatography/mass spectrometry. J. Dent. 1998, 26, 137-145. [CrossRef]

14. Ferracane, J.L.; Condon, J.R. Rate of elution of leachable components from composite. Dent. Mater. Off. Publ. Acad. Dent. Mater. 1990, 6, 282-287. [CrossRef]

15. Geurtsen, W.; Leyhausen, G. Chemical-Biological Interactions of the resin monomer triethyleneglycol-dimethacrylate (TEGDMA). J. Dent. Res. 2001, 80, 2046-2050. [CrossRef]

16. Hansel, C.; Leyhausen, G.; Mai, U.E.; Geurtsen, W. Effects of various resin composite (co)monomers and extracts on two caries-associated micro-organisms in vitro. J. Dent. Res. 1998, 77, 60-67. [CrossRef] [PubMed]

17. Schweikl, H.; Spagnuolo, G.; Schmalz, G. Genetic and cellular toxicology of dental resin monomers. J. Dent. Res. 2006, 85, 870-877. [CrossRef] [PubMed]

18. Tauböck, T.T.; Marovic, D.; Zeljezic, D.; Steingruber, A.D.; Attin, T.; Tarle, Z. Genotoxic potential of dental bulk-fill resin composites. Dent. Mater. Off. Publ. Acad. Dent. Mater. 2017, 33, 788-795. [CrossRef]

19. Sarrett, D.C. Clinical challenges and the relevance of materials testing for posterior composite restorations. Dent. Mater. Off. Publ. Acad. Dent. Mater. 2005, 21, 9-20. [CrossRef]

20. Becher, R.; Kopperud, H.; Al, R.; Samuelsen, J.; Morisbak, E.; Dahlman, H.; Lilleaas, E.; Dahl, J. Pattern of cell death after in vitro exposure to GDMA, TEGDMA, HEMA and two compomer extracts. Dent. Mater. Off. Publ. Acad. Dent. Mater. 2006, 22, 630-640. [CrossRef] [PubMed]

21. De Nys, S.; Putzeys, E.; Vervliet, P.; Covaci, A.; Boonen, I.; Elskens, M.; Vanoirbeek, J.; Godderis, L.; Van Meerbeek, B.; Van Landuyt, K.L.; et al. A novel high sensitivity UPLC-MS/MS method for the evaluation of bisphenol A leaching from dental materials. Sci. Rep. 2018, 8, 6981. [CrossRef]

22. Sonkaya, E.; Kürklü, Z.G.B.; Bakır, Ş. Effect of Polymerization Time on Residual Monomer Release in Dental Composite: In Vitro Study. Int. J. Polym. Sci. 2021, 2021, e8101075. [CrossRef]

23. Łagocka, R.; Mazurek-Mochol, M.; Jakubowska, K.; Bendyk-Szeffer, M.; Chlubek, D.; Buczkowska-Radlińska, J. Analysis of Base Monomer Elution from 3 Flowable Bulk-Fill Composite Resins Using High Performance Liquid Chromatography (HPLC). Med. Sci. Monit. Int. Med. J. Exp. Clin. Res. 2018, 24, 4679-4690. [CrossRef]

24. Pongprueksa, P.; De Munck, J.; Duca, R.C.; Poels, K.; Covaci, A.; Hoet, P.; Godderis, L.; Van Meerbeek, B.; Van Landuyt, K.L. Monomer elution in relation to degree of conversion for different types of composite. J. Dent. 2015, 43, 1448-1455. [CrossRef] [PubMed]

25. Tuna, E.B.; Aktoren, O.; Oshida, Y.; Gencay, K. Elution of residual monomers from dental composite materials. Eur. J. Paediatr. Dent. 2010, 11, 110-114. 
26. Darmani, H.; Al-Hiyasat, A.S. The effects of BIS-GMA and TEG-DMA on female mouse fertility. Dent. Mater. Off. Publ. Acad. Dent. Mater. 2006, 22, 353-358. [CrossRef]

27. Moharamzadeh, K.; Van Noort, R.; Brook, I.M.; Scutt, A.M. Cytotoxicity of resin monomers on human gingival fibroblasts and HaCaT keratinocytes. Dent. Mater. Off. Publ. Acad. Dent. Mater. 2007, 23, 40-44. [CrossRef] [PubMed]

28. Issa, Y.; Watts, D.C.; Brunton, P.A.; Waters, C.M.; Duxbury, A.J. Resin composite monomers alter MTT and LDH activity of human gingival fibroblasts in vitro. Dent. Mater. Off. Publ. Acad. Dent. Mater. 2004, 20, 12-20. [CrossRef]

29. Schneider, T.R.; Hakami-Tafreshi, R.; Tomasino-Perez, A.; Tayebi, L.; Lobner, D. Effects of dental composite resin monomers on dental pulp cells. Dent. Mater. J. 2019, 38, 579-583. [CrossRef]

30. Walters, N.J.; Xia, W.; Salih, V.; Ashley, P.F.; Young, A.M. Poly(propylene glycol) and urethane dimethacrylates improve conversion of dental composites and reveal complexity of cytocompatibility testing. Dent. Mater. 2016, 32, 264-277. [CrossRef] [PubMed]

31. Krifka, S.; Spagnuolo, G.; Schmalz, G.; Schweikl, H. A review of adaptive mechanisms in cell responses towards oxidative stress caused by dental resin monomers. Biomaterials 2013, 34, 4555-4563. [CrossRef]

32. Cytotoxic and Biological Effects of Bulk Fill Composites on Rat Cortical Neuron Cells I SpringerLink [Internet]. Available online: https: / /link.springer.com/article/10.1007\%2Fs10266-018-0354-5 (accessed on 2 December 2021).

33. Srivastava, K.C.; Shrivastava, D. Analysis of plasma lipid peroxidation and antioxidant enzymes status in patients of oral leukoplakia: A case control study. J. Int. Soc. Prev. Community Dent. 2016, 6 (Suppl. 3), S213-S218. [CrossRef]

34. Thompson, L.R.; Miller, E.G.; Bowles, W.H. Leaching of unpolymerized materials from orthodontic bonding resin. J. Dent. Res. 1982, 61, 989-992. [CrossRef]

35. Geurtsen, W. Substances released from dental resin composites and glass ionomer cements. Eur. J. Oral Sci. 1998, 106 Pt 2, 687-695. [CrossRef]

36. Tanaka, K.; Taira, M.; Shintani, H.; Wakasa, K.; Yamaki, M. Residual monomers (TEGDMA and Bis-GMA) of a set visible-lightcured dental composite resin when immersed in water. J. Oral Rehabil. 1991, 18, 353-362. [CrossRef]

37. Cebe, M.A.; Cebe, F.; Cengiz, M.F.; Cetin, A.R.; Arpag, O.F.; Ozturk, B. Elution of monomer from different bulk fill dental composite resins. Dent. Mater. Off. Publ. Acad. Dent. Mater. 2015, 31, e141-e149. [CrossRef] [PubMed]

38. Paula, A.B.; Toste, D.; Marinho, A.; Amaro, I.; Marto, C.-M.; Coelho, A.; Marques-Ferreira, M.; Carrilho, E. Once Resin Composites and Dental Sealants Release Bisphenol-A, How Might This Affect Our Clinical Management?-A Systematic Review. Int. J. Environ. Res. Public Health 2019, 16, 1627. [CrossRef] [PubMed]

39. Tabatabaee, M.H.; Arami, S.; Ghavam, M.; Rezaii, A. Monomer Release from Nanofilled and Microhybrid Dental Composites after Bleaching. J. Dent. 2014, 11, 56-66.

40. Yap, A.U.J.; Han, V.T.S.; Soh, M.S.; Siow, K.S. Elution of leachable components from composites after LED and halogen light irradiation. Oper. Dent. 2004, 29, 448-453. [PubMed]

41. Polydorou, O.; Trittler, R.; Hellwig, E.; Kümmerer, K. Elution of monomers from two conventional dental composite materials. Dent. Mater. Off. Publ. Acad. Dent. Mater. 2007, 23, 1535-1541. [CrossRef]

42. Komurcuoglu, E.; Olmez, S.; Vural, N. Evaluation of residual monomer elimination methods in three different fissure sealants in vitro. J. Oral Rehabil. 2005, 32, 116-121. [CrossRef] [PubMed]

43. Stansbury, J.W.; Dickens, S.H. Determination of double bond conversion in dental resins by near infrared spectroscopy. Dent. Mater. Off. Publ. Acad. Dent. Mater. 2001, 17, 71-79. [CrossRef] 